\section{Einäugige und Blinde}

\author{
B. Gurtner
}

Sie unterzeichneten ihre Briefe mit vorzüglicher Hochachtung. Dennoch hielt sich die gegenseitige Wertschätzung der sehr geehrten Herren Kollegen in Grenzen. Nur unwillig beantworteten viele Praktiker die Rückfragen der SUVA-Ärzte. Heute werden auch knallharte Schreiben mit freundlichen Grüssen abgefedert, doch besteht nach wie vor ein Misstrauen zwischen den Frontkämpfern mit täglichem Patientenkontakt und den für eine Behörde oder Versicherung einsitzenden Büro-Doktoren. Auch in kriegsführenden Armeen gibt es Spannungen zwischen Truppenkommandanten und Stabsoffizieren, die weit vom Schuss ihre Befehle ausbrüten. Ich hoffe, dass eine Gynäkologin gegenüber ihrer mitfraulichen Kantonsärztin keine solchen Vorurteile pflegen würde, und verwende daher im folgenden nur männliche Bezeichnungen für die bösen Buben.

Die Vertrauensärzte der Krankenversicherungen kämpfen seit jeher gegen das ungeliebte Image des ewig ablehnenden und verweigernden "Dr. No», wie man ihre Amtsbrüder in den USA nennt [1]. Der Einfluss administrativer oder beamteter Ärzte auf medizinische Entscheidungen hat auch bei uns in den letzten Jahren stark zugenommen, viel Ärger provoziert, aber nicht nur Negatives bewirkt. Die Indikationsstellungen für einige häufige Untersuchungen und Operationen wurden präzisiert, das Betreuungsnetz nach verkürzten Spitalaufenthalten enger geknüpft und ein verstärktes Qualitäts- und Kostenbewusstsein geschaffen. Von fraglichem Nutzen bleibt aber die alle Bereiche überschwemmende Datenflut für Leistungserfassung und Statistik. Lange Zeit begnügten sich die Kostenträger mit einem kleinen Kreuzchen zur Beantwortung der Frage Unfall $\square$ oder Krankheit $\square$, sie bezahlten blind. Dann drückten sie nur noch ein Auge zu und verlangten wenigstens eine Etagenbezeichnung: Herzinfarkt oder Lungenkrebs konnten verschleiernd unter dem Sammelbegriff "Brustleiden" gemeldet werden, weil man noch darauf achtete, die genaue Diagnose als schützenswertes Patientengeheimnis nicht an Unbefugte weiterzugeben. Nun aber drängten Versicherungen und Behörden auf stets präzisere Angaben. Kurze Zeit genügte ein zweistelliger kantonaler Code, dann kam die dreistellige schweizerische VESKA-Statistik und schliesslich die perfektionierte, einzig von Professionellen zu beherrschende internationale Codierkunst mit ICD-10 und CHOP. Das Vertrauen von Vertrauensärzten lässt sich nur noch mit E-mailierten Fakten gewinnen.
Für Schlüsselpositionen der Managed Care sind Mediziner gesucht mit zusätzlicher Ausbildung in Gesundheitsökonomie. Das Zweitstudium sollte erst nach vielen Jahren ärztlicher Erfahrung folgen. Einige Kollegen haben so eine Midlife-Crisis gelöst, andere sind nach der beruflichen Neuorientierung erst recht ins Schleudern geraten. Die Umstellung vom Partner des einzelnen Patienten zum Anwalt von übergeordneten ökonomischen Interessen ist schwer, nicht jeder Helfer wird ein guter Bremser. Es ist schwierig und unbefriedigend zugleich, Entscheidungen über Versicherte zu fällen, die man nicht persönlich gesehen hat. Problematisch ist auch der rasche Autoritätsverlust bei den aktiven Kollegen, wenn ein medizinischer Manager den unmittelbaren Bezug zum ärztlichen Alltag aufgibt.

Solange es zu wenig interdisziplinär geschulte Fachleute gibt, können frühreife Einäugige als Könige im Reich der Betriebsblinden herrschen. Es kommt zur klassischen Konstellation: Im Tennisclub ist er der grösste Chirurg, im Operationssaal der beste Tennisspieler. Ökonomen betrachten Mediziner schon kurz nach dem Staatsexamen als ärztliche Experten, und Kliniker akzeptieren die gleichen Jungärzte als qualitätsfordernde Projektpiloten, weil sie ökonomisches Basiswissen und das zugehörige Fachvokabular schnellbleichend erworben haben. Vice-versa gilt das ebenso für Absolventen von Handelshochschulen, wenn sie sich nach kurzen Klettertouren auf den Papierbergen einer Gesundheitsdirektion als Spezialisten für Medizinisches Management andienern.

Es ist der fachspezifische Slang, der jenseits der professionellen Sprachgrenze den Nimbus des Erfahrenen verleiht. Auch unter Golfern, Seglern oder Jägern fühlt man sich ausgesperrt, wenn man ihren Jargon nicht versteht. Mediziner werden durch Benchmarking und Monte-Carlo-Simulationen beeindruckt, die Ökonomen ihrerseits durch Bioverfügbarkeit und First-Pass-Effekte. Wer mit Begriffen, die man selbst nicht erfassen kann, leichthin jongliert, wird als Zauberkünstler bestaunt. Die blauen Wunder folgen später. Immerhin, es ist Zeit, dass wir reaktionären Nostalgiker unsere lebhaften Abwehrreflexe verlieren und erkennen, dass die Einbindung von kostennützlichem Fachverstand in ärztliche Entscheidungen allzulange unterblieben ist. So könnten auch einäugige Medizinalökonomen jenen weiterhelfen, die im gesundheitspolitischen Nebel die Orientierung völlig verloren haben. Wenig Erleuchtung bringen aber Junior Consultants, die als Apostel der neoliberalen Heilsbotschaft ausgesandt werden. Ob ihre vorfabrizierten teuren Ratschläge für Spitalfusionen und Betriebsschliessungen als aktive oder passive Sterbehilfe $\mathrm{zu}$ werten sind, überlasse ich dem gnädigen Urteil der sehr geehrten Leserschaft.
Korrespondenz:

Dr. med. Bernhard Gurtner

Eggstrasse 76

CH-8620 Wetzikon

\section{Literatur}

1 Bodenheimer T, Casalino L. Executives with white coats the work and world view of managed-care medical directors. N Engl J Med 1999;341:1945-8, 2029-32. 